\title{
Time-Delay Effects on DC Characteristics of Peak Current Controlled Power LED Drivers
}

\author{
Young-Seok Jung ${ }^{*}$ and Marn-Go Kim ${ }^{\dagger}$ \\ *Dept. of Mechanical \& Automotive Eng., Pukyong National University, Busan, Korea \\ ${ }^{\dagger}$ Dept. of Control \& Instrumentation Eng., Pukyong National University, Busan, Korea
}

\begin{abstract}
New discrete time domain models for the peak current controlled (PCC) power LED drivers in continuous conduction mode include for the first time the effects of the time delay in the pulse-width-modulator. Realistic amounts of time delay are found to have significant effects on the average output LED current and on the critical inductor value at the boundary between the two conduction modes. Especially, the time delay can provide an accurate LED current for the PCC buck converter with a wide input voltage. The models can also predict the critical inductor value at the mode boundary as functions of the input voltage and the time delay. The overshoot of the peak inductor current due to the time delay results in the increase of the average output current and the reduction of the critical inductor value at the mode boundary in all converters. Experimental results are presented for the PCC buck LED driver with constant-frequency controller.
\end{abstract}

Key words: Time-delay effect; Peak current control; Power LED drivers; Average output current; PWM DC to DC converters

\section{INTRODUCTION}

In the past few years, light-emitting diode (LED) technology has emerged as a promising technology for residential, automotive, decorative and medical applications. This is mainly caused by the enhanced efficiency, energy savings and flexibility, and the long lifetime of up to 100,000 hours. Today, LEDs are available for various colors and they are suitable for white illumination [1].

The luminous flux of LEDs is mostly determined by the LED forward current. Controlling the current accurately is a challenge when each LED has a large manufacturing tolerance in its forward voltage as shown in TABLE I [2]. Furthermore, the forward voltage $V_{F}$ also varies over temperature with negative temperature coefficient. Therefore, current mode control is needed to achieve constant brightness

Manuscript received Aug. 23, 2011; revised Jul. 20, 2012.

Recommended for publication by Associate Editor Se-Kyo Chung.

†Corresponding Author: mgkim@pknu.ac.kr

Tel: +82-51-629-6330, Fax: +82-51-629-6305, Pukyong Nat'l Univ.

* Dept. of Mechanical \& Automotive Eng., Pukyong National University, Korea of LEDs [3], [4].

Current mode control is a commonly adopted regulation method for pulse-width modulated (PWM) DC to DC converters because of its inherent features such as short-circuit and overload protection, faster response and pulse-by-pulse control. It is commonly believed that for applications with duty cycle $D<0.5$, the current loop is stable for current mode control without slope compensation. If the required duty cycle is low enough in applications, there is no need for slope compensation, thereby avoiding extra circuitry and as a result, reducing size.

Modeling of current mode controlled converters has been focused on multi-loop regulators with output voltage feedback [5], [6]. In multi-loop regulators, a current controlled power stage inside the conventional output voltage feedback loop constitutes a multi-loop feedback. The outer voltage feedback loop provides the regulated output voltage of converters.

However, LEDs require a stabilized output current. The purpose of this paper is to investigate the time-delay effects on the average output current and the critical inductor value 
at the boundary between the continuous and discontinuous conduction modes in the peak current controlled (PCC) LED drivers without the outer voltage feedback loop.

One new result of the analysis is that the average output current of the PCC buck LED driver is insensitive to input voltage variations when a realistic amount of time delay of 0.4-0.6 $\mu \mathrm{s}$ exists in the control circuit, which is different from the analytical result of the previous works [3], [4], where the time delay is assumed to be zero. On the other hand, the average output current of the PCC boost and buck-boost converters is varied over a wide range with increasing the input voltage. Therefore, the two topologies in the continuous conduction mode are poor for the LED drivers in wide input voltage applications. A second result is that the average output current is affected only by the time delay at turn off and irrelevant to the time delay at turn on in PCC converters. The time-delay effects on the critical inductor value at the boundary between the two conduction modes are investigated too. As the time delay increases, the critical inductor value is reduced in all converters.

TABLE I

EXAMPLE OF LED FORWARD VOLTAGE VARIATIONS

\begin{tabular}{|c|c|c|c|c|}
\hline \multirow{2}{*}{$\begin{array}{c}\text { Z-power } \\
\text { LED }\end{array}$} & \multicolumn{3}{|c|}{$V_{F} @ 25^{\circ} \mathrm{C}, I_{F}=350 \mathrm{~mA}$} & \multirow{2}{*}{$\begin{array}{c}V_{F} \\
\text { deviation }\end{array}$} \\
\hline & Min & Typ & $\operatorname{Max}$ & \\
\hline $\begin{array}{c}\text { White, Green, } \\
\text { Blue }\end{array}$ & 3.0 & 3.25 & 4.0 & $\begin{array}{c}17.2 \\
\%\end{array}$ \\
\hline Red & 2.0 & 2.3 & 3.0 & $\begin{array}{c}23.4 \\
\%\end{array}$ \\
\hline
\end{tabular}

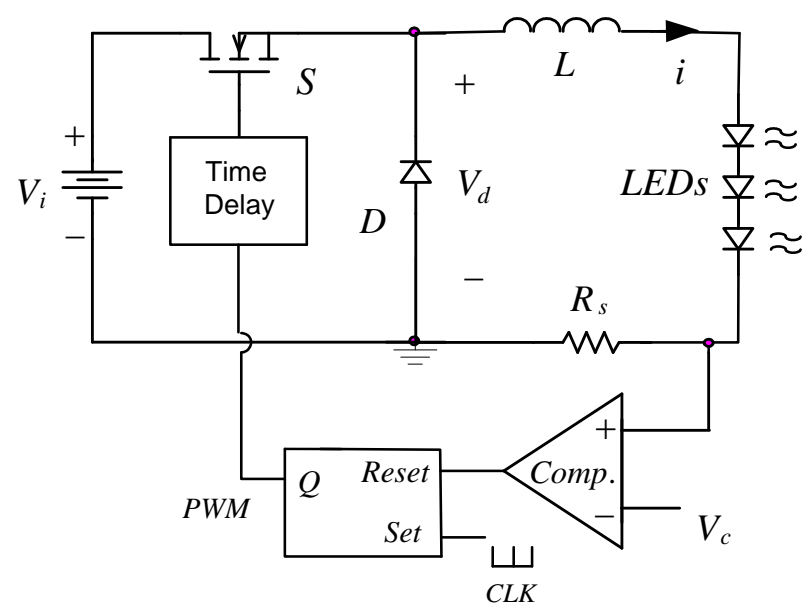

Fig. 1. PCC buck LED driver with constant-frequency controller.

\section{Discrete Time DOMAin MOdeling For PCC POWER LED DRIVERS}

Fig. 1 shows a PCC buck LED driver without slope compensation. Power LEDs require a stabilized output current of $350 \mathrm{~mA}$ and more, and have to be supplied by switched mode power supplies to improve the efficiency. By adding a shunt resistor $R_{S}$ in series to the inductor, the current can be measured via the voltage at the shunt $R_{s}$, so that standard circuit topologies and control schemes can be applied. The measured voltage at the shunt $R_{s}$ has to be very small to avoid additional losses. Thus, both the controller and the shunt resistor have to be connected to common ground.

\section{A. Derivation of the Average Output LED Current for the Continuous Conduction Mode}

The clock signal is applied to initiate the switch ON-time uniformly at the switching, or clock, frequency $f_{s}=1 / T_{s}$. The switch ON-time is terminated when the inductor current reaches a value proportional to the control signal, where the proportionality factor $R_{S}$ is the ratio between the voltage presented to the comparator and the current ramp that produces it.

The relationship is determined at the comparator input, whose detailed waveforms are shown in Fig. 2. The control voltage signal is scaled to equivalent current signal by the proportionality factor $R_{s}$. One comparator input carries the control current $V_{c} / R_{s}$ and the other input carries the inductor current. However, the instantaneous inductor current has a positive ramp of slope $+m_{1}$ when the power switch is $\mathrm{ON}$ and a negative ramp of slope $-m_{2}$ when the switch is OFF, and the duty ratio $d_{k}$ is determined by intersection of the two comparator inputs which, from the geometry of the waveform diagram of Fig. 2(a), is given by

$$
i_{k}+m_{1} T_{s} d_{k}=\frac{V_{c}}{R_{s}} .
$$

This switching control law [7] is termed as the threshold condition [8] or the constraint condition [9].

From the figure, discrete time domain equation for the converter can be represented as

$$
i_{k+1}=i_{k}+m_{1} T_{s} d_{k}-m_{2} T_{s}\left(1-d_{k}\right)
$$

If there is a time delay at turn off in the control circuit, the switch does not turn off when the inductor current reaches the control input $V_{c} / R_{s}$, rather it turns off after some time delay. Due to this delay, the inductor current has an overshoot over 
$V_{c} / R_{s}$ as shown in Fig. 2 (b). Fig. 3 shows the experimental waveforms when control delays are changed. The turn-on delay $t_{d n}$ can not affect the switching control law. The peak inductor current is altered only by the turn-off delay $t_{d f}$. When the control circuit has a time delay at turn off, the switching control law (1) should be modified by

$$
i_{k}+m_{1} T_{s} d_{k}=\frac{V_{c}}{R_{s}}+m_{1} t_{d f}
$$

where $t_{d f}$ is a time delay at turn off. The switching law is irrelevant to the turn-on delay $t_{d n}$ in PCC converters.

In the steady-state, setting $i_{k+1}=i_{k}=I, m_{1}=M_{1}$, $m_{2}=M_{2}, d_{k}=D$, and $t_{d f}=T_{d f}$, (2) and (3) can be rewritten as

$$
\begin{aligned}
& M_{1} T_{s} D=M_{2} T_{s}(1-D) \\
& I+M_{1} T_{s} D=\frac{V_{c}}{R_{s}}+M_{1} T_{d f}
\end{aligned}
$$

The steady-state average inductor current is given by

$$
I_{a v g}=I+\frac{M_{1} T_{s} D}{2}=\frac{V_{c}}{R_{s}}+M_{1} T_{d f}-\frac{M_{1} T_{s} D}{2}
$$

All the above equations apply to any converter. The differences between converters result solely from how the inductor ramps $M_{1}$ and $M_{2}$ are dependent upon operating conditions.

Buck Converter: During the switch ON-time the inductor is connected between the input and output voltages $V_{i}$ and $V_{o}$, so

$$
M_{1}=\frac{V_{i}-V_{o}}{L}
$$

During the switch OFF-time the negative slope of the inductor current is given by

$$
M_{2}=\frac{V_{o}}{L}
$$

Substituting (6) and (7) into (4) and (5) gives the following average output LED current:

$$
I_{L E D}=I_{a v g}=\frac{V_{c}}{R_{s}}+\frac{\left(V_{i}-V_{o}\right)}{L} T_{d f}-\frac{V_{o}\left(V_{i}-V_{o}\right)}{2 f_{s} L V_{i}} .
$$

Boost Converter: During the switch ON-time the inductor is connected across the input voltage $V_{i}$, so

$$
M_{1}=\frac{V_{i}}{L} .
$$

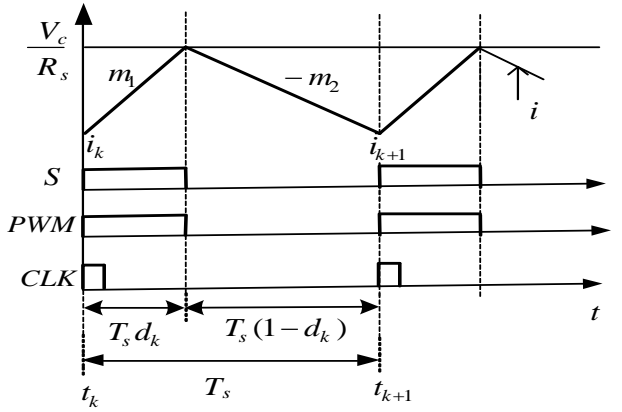

Without time delay

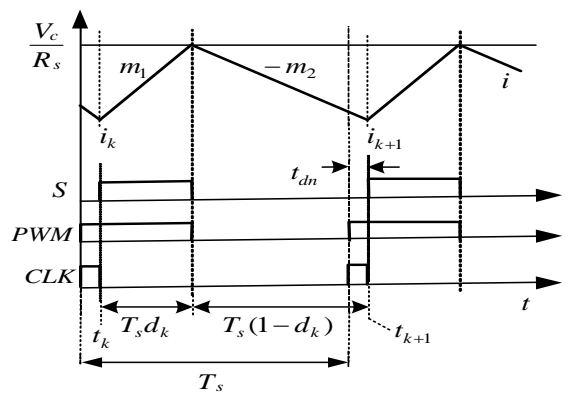

With turn-on delay $t_{d n}$

(a) Switching law: $i_{k}+m_{1} T_{s} d_{k}=\frac{V_{c}}{R_{s}}$

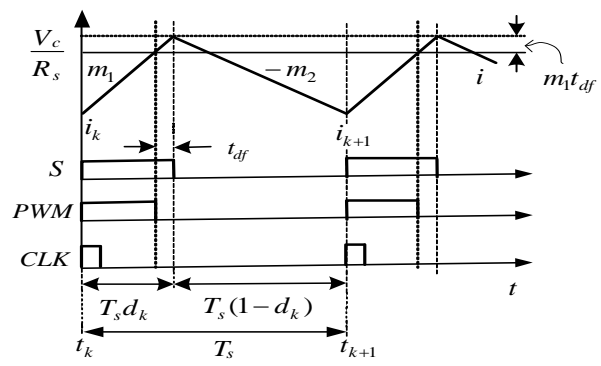

With turn-off delay $t_{d f}$

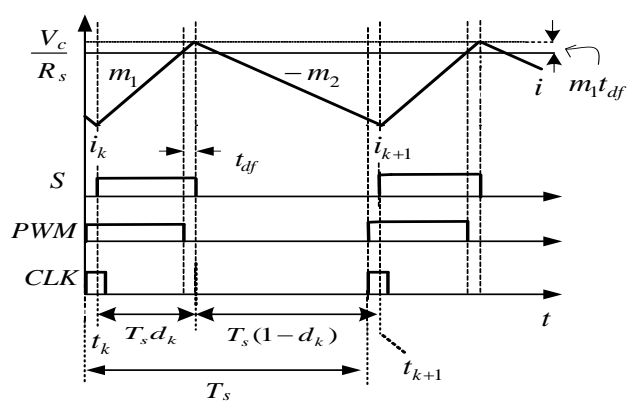

With turn-on and turn-off delays

(b) Switching law: $i_{k}+m_{1} T_{s} d_{k}=\frac{V_{c}}{R_{s}}+m_{1} t_{d f}$

Fig. 2. Key theoretical waveforms with simple peak current control. 


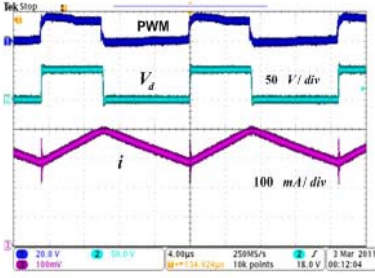

(a) Normal operation.

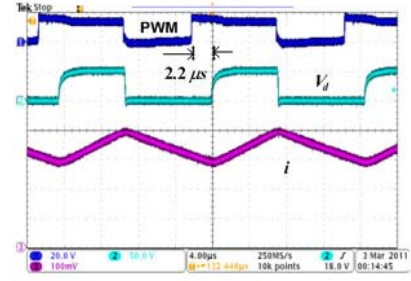

(b) Large time delay $T_{d n}$.

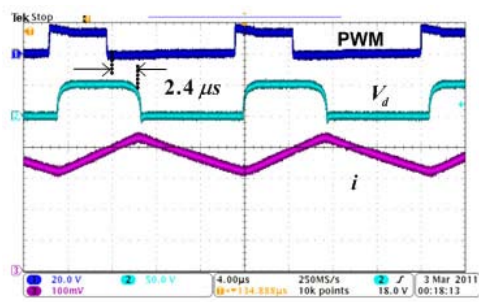

(c) Large time delay $T_{d f}$ at turn-off.

Fig. 3. Peak current variations by change of time delay with constant control input.

During the switch OFF-time the negative slope of the inductor current is given by

$$
M_{2}=\frac{V_{o}-V_{i}}{L} .
$$

To determine the average output LED current of the boost converter, substituting (9) and (10) into (4) and (5) produces

$$
\begin{aligned}
I_{L E D}= & I_{a v g}(1-D) \\
& =\left\{\frac{V_{c}}{R_{s}}+\frac{V_{i}}{L} T_{d f}-\frac{V_{i}\left(V_{o}-V_{i}\right)}{2 f_{s} L V_{o}}\right\}\left(\frac{V_{i}}{V_{o}}\right) .
\end{aligned}
$$

Buck-Boost Converter: As for the boost converter,

$$
M_{1}=\frac{V_{i}}{L} .
$$

During the switch OFF-time,

$$
M_{2}=\frac{V_{o}}{L} \text {. }
$$

As for the boost converter, substituting (12) and (13) into (4) and (5) gives the following average output LED current:

$$
\begin{gathered}
I_{L E D}=I_{a v g}(1-D) \\
=\left\{\frac{V_{c}}{R_{s}}+\frac{V_{i}}{L} T_{d f}-\frac{V_{i} V_{o}}{2 f_{s} L\left(V_{i}+V_{o}\right)}\right\}\left(\frac{V_{i}}{V_{i}+V_{o}}\right)
\end{gathered}
$$

B. Determination of the Critical Inductor Value at the

\section{Boundary between Two Conduction Modes}

The boundary condition between the continuous and discontinuous conduction modes can be determined by setting $I=0$ in (4) as follows.

$$
T_{s}=\left(\frac{1}{M_{1}}+\frac{1}{M_{2}}\right)\left(\frac{V_{c}}{R_{s}}+M_{1} T_{d f}\right) .
$$

This boundary condition can be converted to Cuk's derivations [10] by using $\left(V_{c} / R_{s}+M_{1} T_{d f}\right) / 2=V_{o} / R$ for the buck, and $\left(V_{c} / R_{s}+M_{1} T_{d f}\right)(1-D) / 2=V_{o} / R$ for the boost and buck-boost converters. But, Cuk's model cannot be used to investigate the time-delay effect of the control circuit on the DC characteristics. The point of this article is to derive the equations for the critical inductor values as a function of the time delay when the outer voltage feedback is not employed.

Substituting the ON-time and OFF-time slopes into (15) gives the critical value of the inductor $L_{c}$ at the boundary between the two conduction modes for each converter.

Using (6) and (7), the critical inductor value for the PCC buck converter can be derived as

$$
L_{c}=\left(T_{s}-\frac{V_{i}}{V_{o}} T_{d f}\right) \frac{V_{o}\left(V_{i}-V_{o}\right)}{V_{i}} \frac{R_{s}}{V_{c}} .
$$

Substituting (9)-(10) into (15) gives the critical inductor value for the PCC boost converter as the following

$$
L_{c}=\left(T_{s}-\frac{V_{o}}{V_{o}-V_{i}} T_{d f}\right) \frac{V_{i}\left(V_{o}-V_{i}\right)}{V_{o}} \frac{R_{s}}{V_{c}} .
$$

Using (12)-(13), the critical inductor value of the PCC buck-boost converter can be written as

$$
L_{c}=\left(T_{s}-\frac{V_{i}+V_{o}}{V_{o}} T_{d f}\right) \frac{V_{i} V_{o}}{V_{i}+V_{o}} \frac{R_{s}}{V_{c}} .
$$

When $L>L_{c}$, all the above converters are in the continuous conduction mode.

\section{ANALYSIS Of TIME-DELAY EFFECTS ON DC CHARACTERISTICS}

To analyse the time-delay effects on the DC characteristics of the PCC LED drivers in the continuous inductor current mode, the circuit parameters of $f_{s}=60 \mathrm{kHz}$ and $L=1.36 \mathrm{mH}$ are used.

Using (8), Fig. 4 illustrates the time-delay effect on the average output LED current of the PCC buck LED driver with increasing the input voltage. From the previous works [3], the average output LED current drops with the increase of the input voltage, which is true for $T_{d f}=0$. If there is a delay in the control circuit, the switch does not turn off when the inductor current reaches the control input $V_{c} / R_{s}$, rather it turns off after some time delay. Due to this delay, the inductor current has an overshoot of $M_{1} T_{d f}$ over $V_{c} / R_{s}$. 
This current overshoot compensates for the reduction of the average output current due to the increase of the input voltage. Therefore, the simple peak current control can provide a good current accuracy for the buck LED driver over wide input voltage variations when a proper time delay of approximately 0.4-0.6 $\mu s$ exists in the control circuit. This is a realistic amount of time delay in the control circuit.

The graph of (11) is shown in Fig. 5(a) for $V_{o}=55 \mathrm{~V}, V_{c} / R_{s}=540 \mathrm{~mA}$. The average output LED current varies over a wide range with increasing the input voltage. Therefore, the PCC boost LED driver can not be used for the wide input voltage applications.

Using (14), Fig. 5(b) shows the average output LED current of the PCC buck-boost LED driver for $V_{o}=15 \mathrm{~V}, V_{c} / R_{s}=550 \mathrm{~mA}$. The output LED current varies significantly with increasing the input voltage. Thus, the PCC buck-boost LED driver is poor for wide input voltage applications.

As $T_{d f}$ increases, the average output LED current increases in all of the basic converters. From Figs. 4-5, it can be said that the PCC buck converter is most suitable for the power LED driver, especially in wide input voltage applications.

Using (16)-(18), the time-delay effects on the critical inductor value curve at the boundary between the two conduction modes are shown in Figs. 6-7. As the time delay increases, the critical inductor value is reduced in all converters.

Due to the time delay $T_{d f}$, the peak inductor current has an overshoot of $M_{1} T_{d f}$ over the control input of $V_{c} / R_{s}$, which means the control input of $V_{c} / R_{s}+M_{1} T_{d f}$ when the time delay is zero. This overshoot of the peak inductor current results in the increase of the average output current and the reduction of the critical inductor value at the boundary between two conduction modes in the PCC PWM converters.

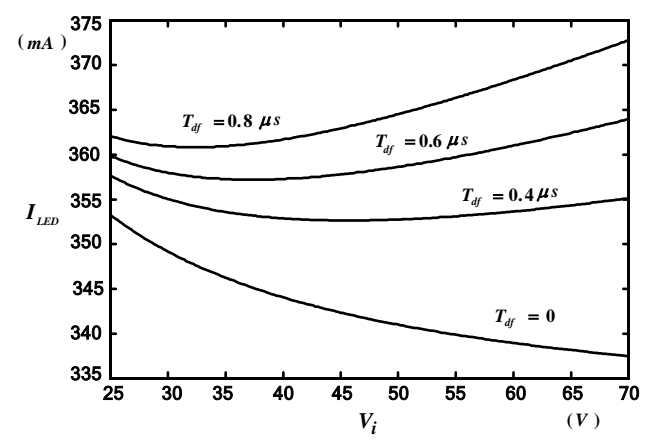

Fig. 4. Time-delay effect on the average output LED current of the PCC buck LED driver $\left(V_{o}=10 \mathrm{~V}, V_{c} / R_{s}=390 \mathrm{~mA}\right)$.

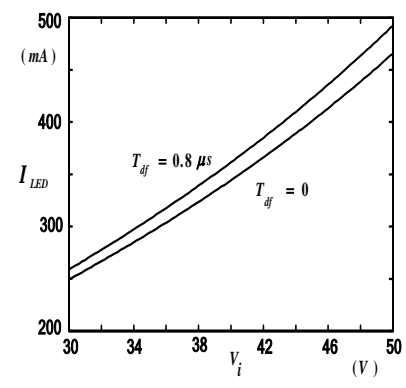

(a) Boost.

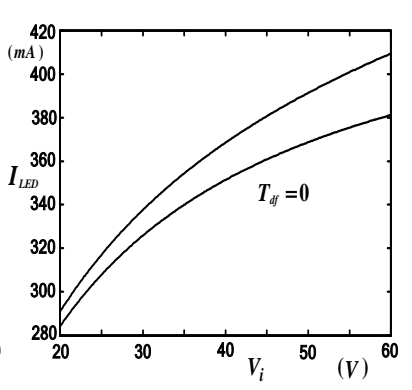

(b) Buck-boost.
Fig. 5. Time-delay effect on the average output LED current of the PCC boost and buck-boost LED drivers.

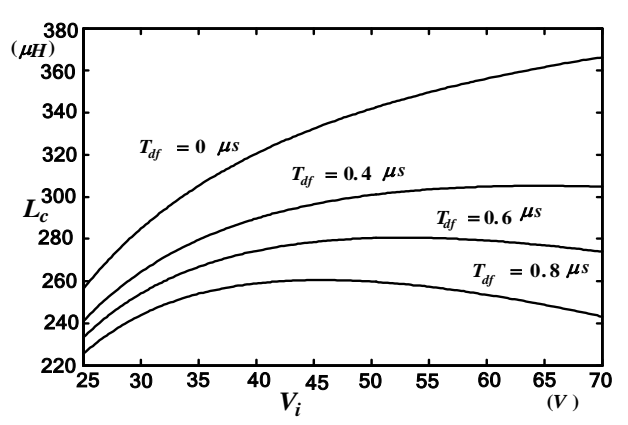

Fig. 6. Time-delay effect on the critical inductor value curve for the PCC buck converter $\left(V_{o}=10 \mathrm{~V}, V_{c} / R_{s}=390 \mathrm{~mA}\right)$.

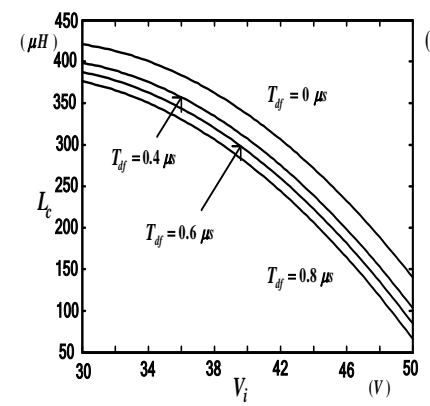

(a) Boost.

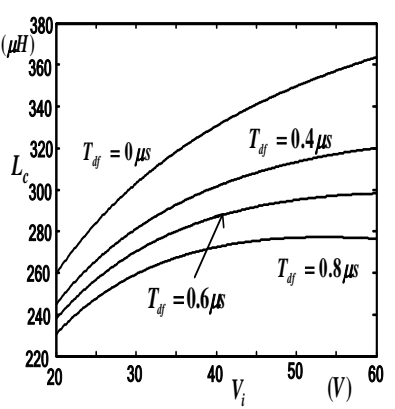

(b) Buck-boost.
Fig. 7. Time-delay effect on the critical inductor value curve for the PCC boost and buck-boost converters.

\section{EXPERIMENTAL EVALUATION}

For performance evaluations, a prototype converter has been constructed as shown in Fig. 8. The constant switching frequency is $58.8 \mathrm{kHz}$. The control IC is CS3842, where no compensation slope is used. The peak control input $V_{c} / R_{S}$ is $390 \mathrm{~mA}$. S is IRF 840 and D is DSEI12-06A. Here, we use pure-white LEDs, Z-POWER w42182, which has a typical current of $350 \mathrm{~mA}$.

This LED forward voltage varies from $2.9 \mathrm{~V}$ to $3.8 \mathrm{~V}$, for a nominal of $3.25 \mathrm{~V}$ [2]. 


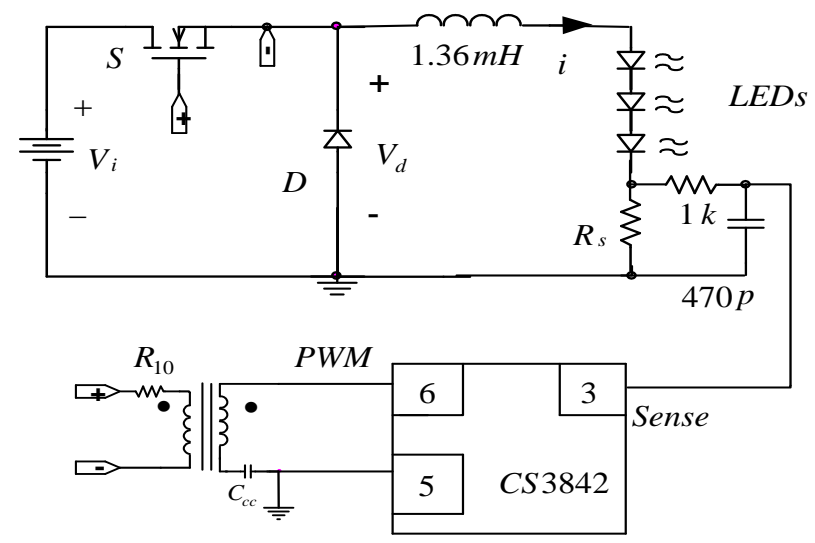

Fig. 8. Experimental PCC buck LED driver ( $f_{s}=58.8 \mathrm{kHz}$, $V_{c} / R_{s}=390 \mathrm{~mA}$ ).

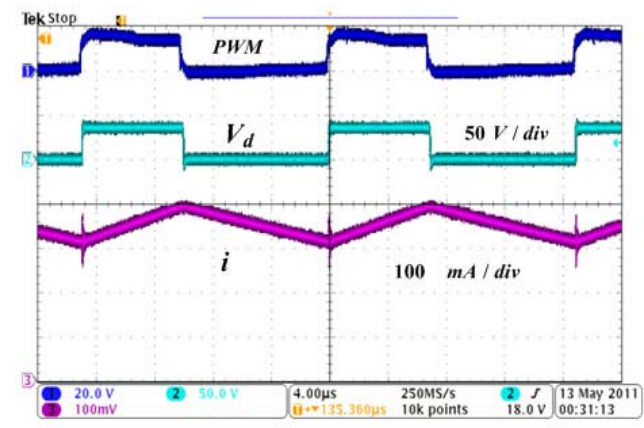

(a) $V_{i}=35 \mathrm{~V}$.

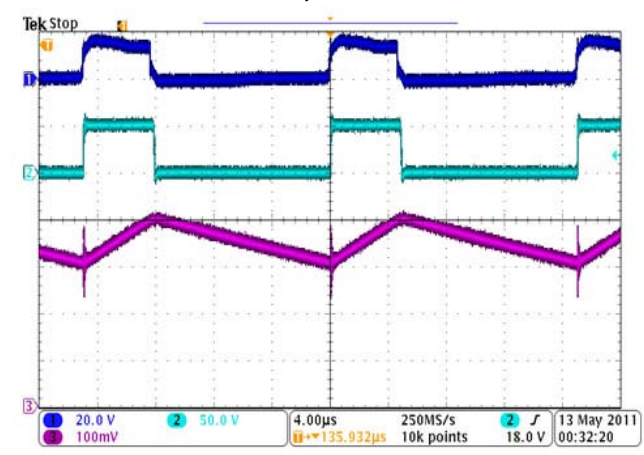

(b) $V_{i}=50 \mathrm{~V}$.

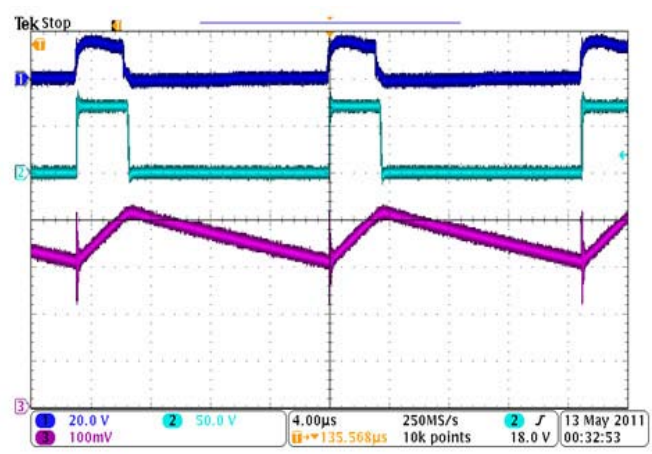

(c) $V_{i}=70 \mathrm{~V}$.

Fig. 9. LED current waveforms with increasing the input voltage $\left(V_{o} \approx 13 V, V_{c} / R_{s}=390 m A\right)$.

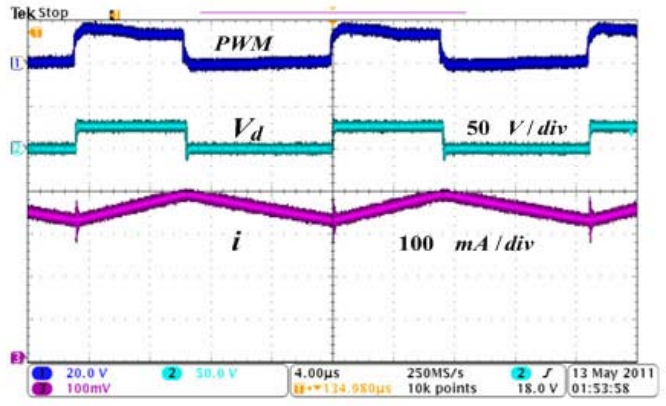

(a) $V_{i}=25 \mathrm{~V}$.

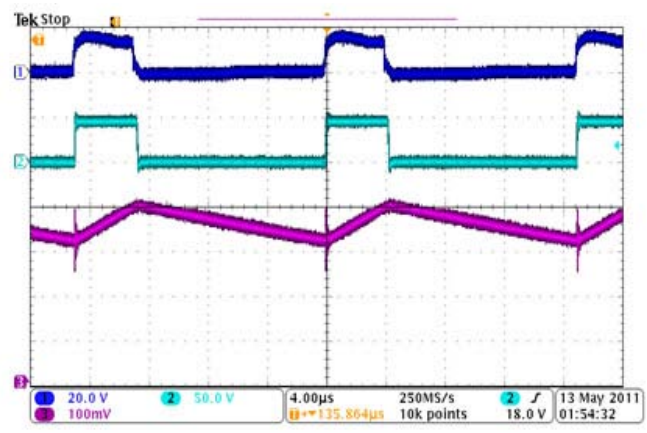

(b) $V_{i}=45 \mathrm{~V}$.

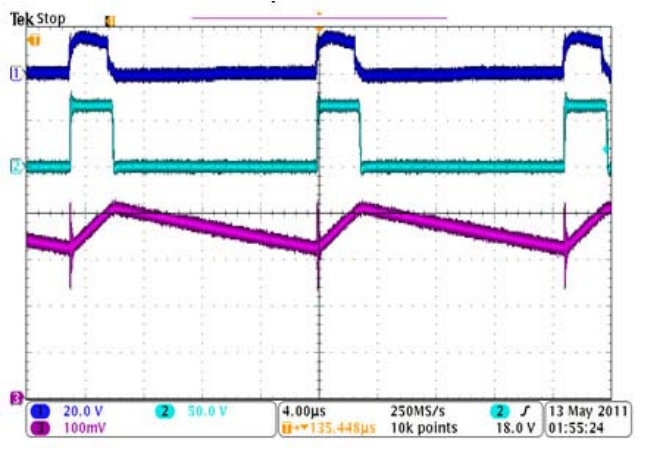

(c) $V_{i}=65 \mathrm{~V}$.

Fig. 10. LED current waveforms with increasing the input voltage when the output voltage is varied ( $V_{o} \approx 9.75 \mathrm{~V}$, $\left.V_{c} / R_{s}=390 \mathrm{~mA}\right)$.

With four LEDs connected in series, which provides a typical loading voltage of approximately (3.25V X 4 LEDs in series) $13 \mathrm{~V}$, the measured LED currents are shown in Fig. 9. As the input voltage increases, the average LED current doesn't decrease in this figure due to the time delay in the control circuit. This experimental result is different from the previous analytical result obtained from assuming $T_{d f}=0$. Due to the time delay in the control circuit, the average LED current is insensitive to the input voltage variations in the PCC buck converter. Fig. 10 shows the measured LED current waveforms at a typical output voltage of approximately (3.25V X 3 LEDs in series) 9.75V, which means the output voltage variation of about $25 \%$ compared to the output voltage of $13 \mathrm{~V}$ in Fig. 9. This experimental result shows that the average LED current of the PCC buck 


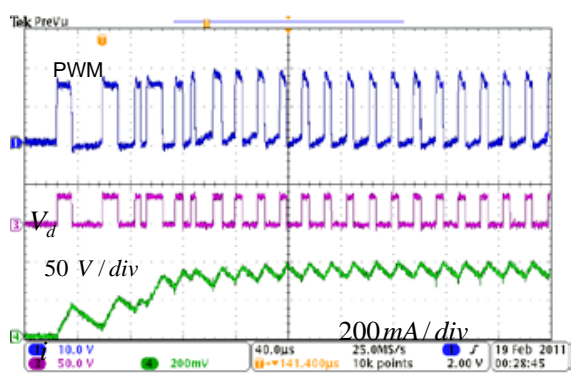

(a) $V_{i}=35 \mathrm{~V}$.

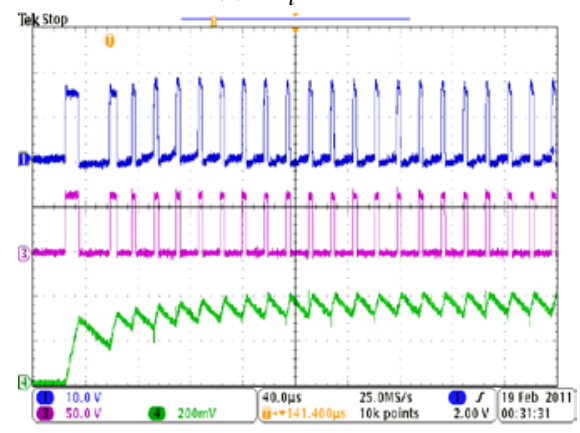

(b) $V_{i}=65 \mathrm{~V}$.

Fig. 11. Start-up transient responses of Fig. 8.

$\left(V_{o} \approx 13 V, V_{c} / R_{s}=390 m A\right)$.

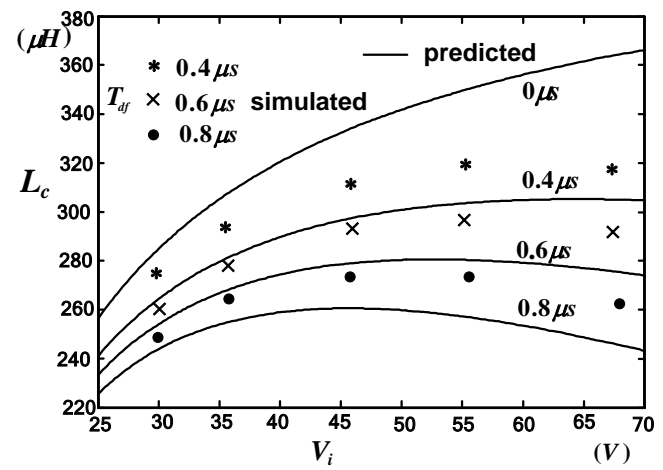

Fig. 12. Simulated critical inductor values for the PCC buck converter $\left(V_{o}=10 \mathrm{~V}, V_{c} / R_{s}=390 \mathrm{~mA}\right)$.

converter doesn't vary significantly due to the change of the LED forward voltage. From Figs. 9-10, it can be said that the PCC buck converter is excellent for the LED drivers in wide input voltage applications.

The start-up transient responses are shown in Fig. 11. The LED current is well limited below the peak current as expected. Fig. 12 shows the simulated critical inductor values of the PCC buck converter at the boundary between the two conduction modes, the simulated data are obtained from PSPICE simulation. The small discrepancy between the predicted and the simulated critical inductor values is mainly due to both the forward voltage of the freewheeling diode D and the conduction voltage of the active switch S.

\section{CONCLUSION}

This proposed discrete time domain modeling describes for the first time the effects of control delay on the average output current and the critical inductor value at the boundary between the two conduction modes in the PCC power LED drivers. The total time delay is the sum of all the propagation delays from the PWM comparator to the power switch. Due to this delay, the inductor current has an overshoot over the peak current control input. This overshoot of the peak inductor current results in the increase of the average output current and the reduction of the critical inductor value at the boundary between the two conduction modes in all converters.

When the input voltage varies, the average output LED current of the boost and buck-boost LED drivers operating in continuous conduction mode with the simple peak current controller, varies over a wide range. These two topologies are not suitable for the power LED drivers in wide input voltage applications. On the other hand, the PCC buck LED driver maintains the average output LED current relatively at a constant level with increasing the input voltage when a realistic amount of time delay exists in the control circuit. Because the current overshoot by the time delay compensates for the average output current reduction from increasing the input voltage in the PCC buck converter. Thus the PCC buck converter operating in the continuous conduction mode is most suitable for the power LED driver, especially in wide input voltage applications.

\section{REFERENCES}

[1] H. van der Broeck, G. Sauerlander and M. Wendt, "Power drivers and control schemes for LEDs," in Proceedings of IEEE-APEC”07, pp. 1319-1325, 2007.

[2] Seoul Semiconductor Co., LTD. "Z-power LED Series Technical Datasheet for X4218X,” http://www.acriche.com/kr/, 2009.

[3] O. Ronat, P. Green and S. Ragona, "Accurate current control to drive high power LED strings," in Proceedings of IEEE-APEC”06, pp. 376-380, 2006.

[4] I.-H. Oh, "An analysis of current accuracies in peak and hysteretic current controlled power LED drivers," in Proceedings of IEEE-APEC”08, pp. 572-577, 2008.

[5] R. D. Middlebrook, “Topics in multi-loop regulators and current-mode programming," IEEE Trans. Power Electron., Vol. 2, No. 2, pp. 109-124, Apr. 1987.

[6] G. C. Ioannnidis, G. Charokopos, P. Marabeas and S. N. Manias, “A mixed-mode PWM controller," International Journal of Electronics, Vol. 97, pp. 1423-1438, 2010.

[7] M.G. Kim and M. J. Youn, "A discrete time domain modeling and analysis of controlled series resonant converter," IEEE Trans. Ind. Electron., Vol. 38, pp. 32-40, Feb. 1991. 
[8] F. C. Lee, R. P. Iwens, Y. Yu, and J. E. Triner, "Generalized computer-aided discrete-time modeling and analysis of dc-dc converters," IEEE Trans. Industr. Electron. Contr. Instrum., Vol. 26, pp. 58-69, May 1979.

[9] G.C. Verghese, M.E. Elbuluk, and J.G. Kassakian, “A general approach to sampled-data modeling for power electronic circuit,” IEEE Trans. Power Electronics, Vol. 1, pp. 76-89, Apr. 1986.

[10] S. Cuk and R.D. Middlebrook, “A general unified approach to modeling switching DC-To-DC converters in discontinuous conduction mode," in Proceedings of IEEE-PESC"77, pp. 36-57, 1977.

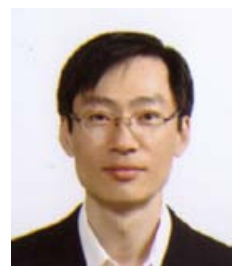

Young-Seok Jung received his B.S., M.S. and ph.D. degrees in Electrical Engineering from the Korea Advanced Institute of Science and Technology (KAIST), Daejon, Korea, in 1992, 1994, and 1999, respectively. He worked for Hyundai Autonet, Powertrain Team, from 1999 to 2002. Since 2002, he has been with the Department of Mechanical \& Automotive Engineering at Pukyong National University, Korea. His research interests are in the area of power converter and variable speed motor drives. Dr. Jung is a member of the Korean Institute of Power Electronics (KIPE).

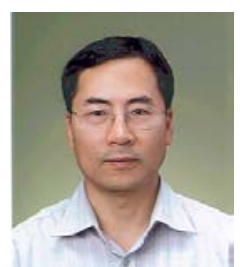

Marn-Go Kim received the B. S. degree in electrical engineering from Kyungpook National University in 1986, and the M. S. and $\mathrm{Ph}$. D. degrees in electrical engineering from Korea Advanced Institute of Science and Technology in 1988 and 1991, respectively. From 1991 to 1994, he was with Korea Telecom Research Center, Seoul, where he served as the leader of a project team for telecom power systems. From 2003 to 2004, he was a Visiting Scholar at Virginia Polytechnic Institute and State University, Blacksburg, VA, USA. Since 1995, he has been with the department of control \& Instrumentation engineering, Pukyong National University, where he is now a professor. His research interests include modeling, analysis, and control of DC/DC converters, power electronics applications, and soft switching converters. Dr. Kim is a member of KIPE and KIEE. 